\title{
PERCEIVED DIFFICULTIES IN LEARNING OF MANDARIN AMONG FOREIGN-LANGUAGE LEARNERS AND STRATEGIES TO MITIGATE THEM
}

\author{
NURUL AIN CHUA ${ }^{1 *}$, AZZA JAUHAR AHMAD TAJUDDIN ${ }^{1}$, YING SOON GOH ${ }^{2}$ \\ AND CHE MOHD ZAID ${ }^{1}$
}

${ }^{1}$ Centre for Fundamental and Continuing Studies, Universiti Malaysia Terengganu, Kuala Nerus, 21020, Terengganu, Malaysia

${ }^{2}$ Academy of Language Studies, Universiti Teknologi MARA Terengganu, Malaysia

*Corresponding author: ain.chua@umt.edu.my

Submitted final draft: 26 March $2020 \quad$ Accepted: 28 August $2020 \quad$ http://doi.org/10.46754/jbsd.2020.09.005

\begin{abstract}
This study explored the hardship faced by foreign-language learners of Mandarin and the strategies applied to overcome them. Literature review found that technology created a positive effect that enhanced the learners' achievement. Nevertheless, it was still doubtful how far the activities advocated by technology or its potential increase in motivation could boost the students' learning. Most techniques, real expansions in education and competence had yet to be proven. The hardship and coping strategies were classified and examined according to quantitative and qualitative methods. The findings indicated that different learners experienced various levels of difficulty, and they had their own coping response. Gender and course stream did not seem to be associated with obstacles. The barriers that triggered incompetence and the ways that learners used to overcome them were explained. The grounds of hardship and response strategies were limited. The actual number of coping methods could be more than reported as learners tended to use whatever strategy that was convenient for them.
\end{abstract}

Keywords: Mandarin, foreign language, learning, hardship, coping

\section{Introduction}

Due to the uniqueness of the brain, some people have the ability to learn and pick up multiple languages easily. The major setback in learning a language is the difficulty in remembering and constructing words using new sounds, rhythms and intonations to smoothly convey thoughts and intentions. In other words, the hardship in learning a foreign language is to gradually develop the materials of a particular language (Brad, 2012). Thus, the practical approach to learning a language has become an essential discussion among researchers. Furthermore, every learner has different capabilities that are influenced by their background, personality, motivation, learning style and purpose.

Numerous studies have tried to resolve the learning challenges from different perspectives. They include steps to overcome anxiety (Hsiao, 2015; Luo, 2015; Ting et al., 2016), motivation to increase performance (Ji et al.,2017; Mohamed \& Wei, 2018), better learning strategied (Chen \& Hsu, 2017; Peipei, 2018; Su, 2018; Sun \& Summers, 2014), improvised speaking methods (Luo, 2015; Yong et al., 2016a; Yong et al., 2016b), and improving intonation perception (Ding et al.,2017; Do et al., 2012; McLoughlin, 2007; Zhang et al.,2008). Some studies also investigated 
the difficulties experienced by learners in technology-aided learning (Lan et al., 2014; Xu \& Peng, 2017; Ying \& Wah, 2016). Most of the studies have looked at learning difficulties from a perspective of researchers, and concrete strategies are explored to see to what extent they may help the students. Thus, many researchers intend to study the differences in learning capability and stimulate endeavours to strengthen self-learning.

Many empirical results showed that technology brings positive impact in learning Mandarin. However, the ability to write in a foreign language is not as easy as speaking it. Therefore, it is essential to study the learning difficulties and the way learners respond to a different context. Teachers must take their learners' pronunciation into consideration during the instructional process and thus, deliberately adjust the instructional approaches to ease learning and make learners comfortable and motivated. It is hoped that the data in this study may be used to develop ways to maintain the learners' interest to continue learning a language. The specific research questions are as below:

1. What are the difficulties in learning Mandarin, and also the differences among learners?

2. How do learners cope with their challenges?

\section{Literature Review}

Previous studies have shown that foreign language learners encountered difficulties such as anxiety, demotivation, uneffective strategies, and poor ability in speaking and perceiving intonations despite using technology-aided learning methods.A study on intonation acquisition have identified five central problems (Yang, 2015). They include learning the intonations without original settings, avoiding the fact of different learning preferences, and overlooking the issue of speakers using the correct intonation as a system of contrasts.

Besides individual learning, the problems were inefficient in the empirical measurement used in production experiments, and, finally, not adjusting for the discrepancy between learners' study subjects with better perception as compared with those with better production. For instance, Kaan et al., (2008) observed attentive and non-attentive ways of processing intonations that were pliable even in adult learners.

The learning of Mandarin is of considerable interest to researchers. Unlike the alphabet system which uses letters to form words, Chinese characters are words of their own, which are represented by the sound of their pronunciation. Therefore, the language requires good memory to recognise all characters and their corresponding sounds. Numerous studies have discovered that the main difficulty in learning Mandarin is using the correct intonation for a Chinese character, known as the pinyin (Jiang \& Cohen, 2018). A Romanised description of a Chinese character can be pronounced in four intonations, and each intonation conveys a vastly different meaning. This is tricky for learners who may pronounce a wrong word if they do not get the right intonation.

A plethora of studies have been conducted to address the issue of Chinese character recognition. In resolving this hardship, beginners are encouraged to sift through their prior knowledge to identify a "tag" in memorizing the characters (Grenfell \& Harris, 2015). In other words, memorizing is the crucial strategy.

It has been observed that learners may improve their fluency in speaking Mandarin through practice (Wang et al., 2014). Bryfonski \& Ma (2019) found that implicit feedback (working memory) could produce considerable improvements in pronunciation compared to explicit 
feedback. Lately, most research is focusing on incorporating technology into learning Mandarin. For instance, Wong et al., (2017) studied a Mobile Computer-supported Collaborative Learning method through an iterative process of (re)designing and testing the collaboration and learning approach with learners.

The legislation of the learning pattern in both modes (with and without the digital technology) was observed, and the exact process of learners being technologically or socially scaffolded to perform their tasks was examined. The learners were observed to prefer the card mode over the phone mode due to the new game strategy (social scaffold). Lu etal., (2014) found that learning Chinese characters via mobile technology (eg. Apple iPod Touch) contained high potential in Chinese language education. The functionality of mobile technology may be utilized to design mobile applications that engage learners in listening, writing and speaking Mandarin independently. In terms of reading and writing difficulties, Liu (2010) investigated Chinese text entry on mobile phones and proposed a model. The empirical results suggest that the model may be used to evaluate the user's performance by assessing their typing of Chinese pinyin texts.

Other studies discussed issues relating to difficulties in learning Mandarin. For example, Hsiao (2015) investigated the anxiety faced by learners and managed to condense its levels that varied according to different tasks of listening, speaking, reading and writing. Learners with high performance goals experienced more anxiety than those with low learning goals. Ji et al., (2017) revealed that task orientation has the most significant impact on learners' motivation to learn Chinese, followed by involvement and equity.

Typically, capable language learners know how to use appropriate strategies to reach their learning goals, whereas ineffective learners are inclined to seek fewer opportunities and may not even know how to use any learning approach. Learners should equip themselves with multiple learning methods, and teachers should utilize appropriate strategies that meet match their learners' needs. The late Jerome Bruner, an American psychologist who made significant contributions to human cognitive psychology, once stated that it was vital for learners to learn how to learn (Williams \& Burden, 1997b). Consequently, the awareness about how to cope with challenges in learning Mandarin is essential and provides useful knowledge in terms of learning strategies. This study may elicit the foreign language learners' practical efforts, which can be utilized by others in enhancing their language proficiency.

Overall, the existing studies have revealed some constructs of difficulties in learning Mandarin. The practitioners have a more accurate view of how students can be pushed and helped to improve their performance; roughly all the research is based on observations from researchers' perspectives. However, the learners' perception of learning hardship and coping strategies are also essential to investigate. Thus, the information gathered from this study includes both perceived by the learners and observed by the researcher.

\section{Materials and method}

The study was a survey that examined the participants' view on the challenges in learning Mandarin and how they responded to them during the instructional process. An adapted questionnaire (Huang, 2000) was used to uncover the learners' perspectives. There were eight questions in section I and seven questions for section II. The information collected included the learners' background, Mandarin usage experience, the hardship they faced, their coping strategies and goals. Data from section I were quantitatively analysed using IBM 
SPSS version 20 (IBM Corp, Armonk, New York, USA). The reliability was determined using Cronbach alpha $(\alpha)$ to determine the internal consistency between the eight items used in the scale in assessing the hardship of Mandarin learning. Table 1 shows that all the items had very high level of internal consistency (Cronbach $\alpha=0.826$ ). This indicated that the items selected were reliable in measuring the construct.

Table 1: The reliability test

\begin{tabular}{lc}
\hline \multicolumn{1}{c}{ Items } & Std. Deviation \\
\hline 1. Pronunciation & 0.65 \\
2. Intonation & 0.704 \\
3. Grammar & 0.729 \\
4. Chinese Characters & 0.771 \\
5. Vocabulary & \\
$\quad$ Enlargement & 0.718 \\
6. Oral Communication & 0.819 \\
7. Giving A Talk & 0.794 \\
8. Learning Composition & 0.612 \\
Cronbach's Alpha $=0.826$ & \\
\hline
\end{tabular}

In section II, there were open-ended questions to dig further into their learning experiences. The data were qualitatively analysed to support the findings. The data was collected in the seventh week. The reason was to provide enough time for the students to reflect on their learning.

The participants comprised 80 learners from the beginners, intermediate and advanced level of Mandarin courses in Universiti Malaysia Terengganu, Kuala Terengganu, Malaysia. Most of them were not acquainted with the language. The participants were chosen using the purposive sampling technique. They were from different degree programmes under the science and social science disciplines. All of them took up the Mandarin course as an additional subject.

\section{Results}

\section{Demography of Learners}

Table 2 shows the students' demographic background. All the Mandarin foreign language learners had not learned the language before. The students were from Level I (44 students, $55 \%$ ) Level II (14 students, $17.5 \%$ ) and Level III (22 students, $27.5 \%)$. Female learners (81.3 $\%$ ) outnumbered males $(18.7 \%)$ by slightly more than four times, and the majority were science students $(57.5 \%)$.

Table 2: Learner's demography

\begin{tabular}{cc}
\hline Demography & Frequency \\
\hline Male & 15 \\
Female & 65 \\
Social science & 34 \\
Science & 46 \\
Level I & 44 \\
Level II & 14 \\
Level III & 22 \\
Malay & 65 \\
Tamil & 12 \\
English & 2 \\
Chinese dialects & 1 \\
\hline
\end{tabular}

\section{Finding 1 Learning Hardship}

The findings on learning hardship is shown in figure 1 . The items measured were indicated as numbers, including pronunciation, intonation, grammar, Chinese characters, vocabulary, oral communication, presentation and learning composition. 


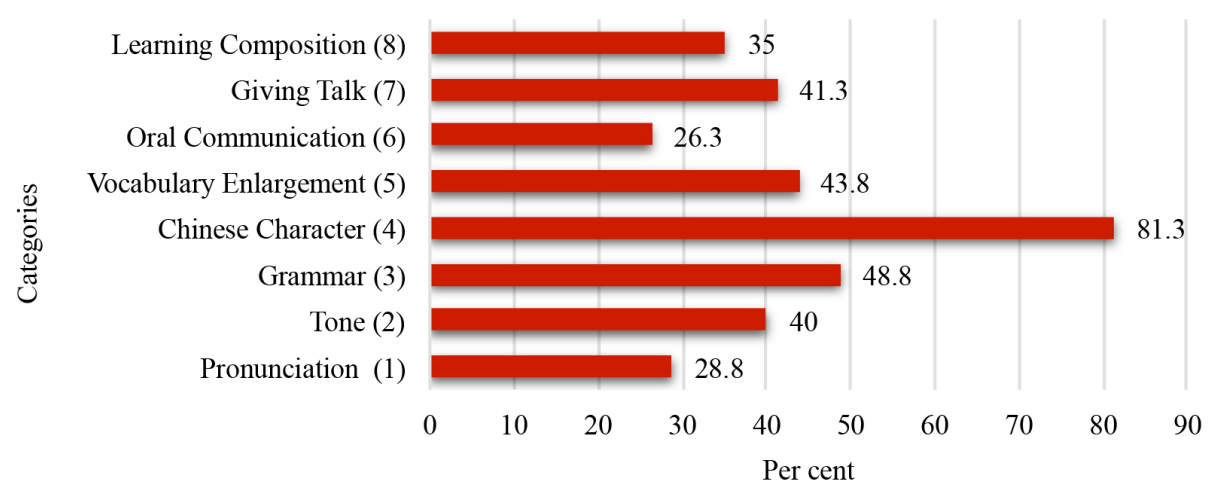

Figure 1: Learning hardship faced by a batch of Mandarin course learners in Universiti Malaysia Terengganu

Figure 1 indicates all the hardship presentation (41.3\%), intonation (40\%), perceived by learners in learning Mandarin. learning composition (35\%), pronunciation The most challenging was Chinese $(28.8 \%)$ and oral communication $(26.3 \%)$. characters $(81.3 \%)$. The second highest Thus, in order to use the language correctly challenge was grammar (48.8\%), followed and fluently, the difficulties in learning by vocabulary enlargement $(43.8 \%)$, intonations and pronunciations must be resolved.

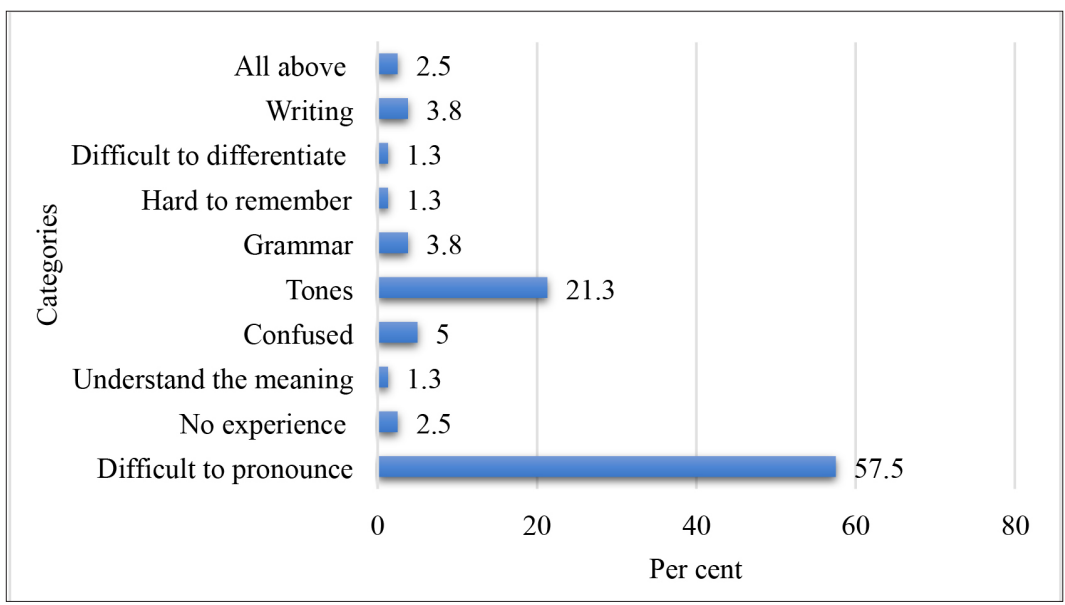

Figure 2: Types of difficulties in learning Mandarin faced by a batch of Universiti Malaysia Terengganu learners.

Figure 2 shows that the biggest difficulty faced by learners was in pronounciation $(57.5 \%)$. The second was intonation $(21.3 \%)$, where learners had great difficulty in identifying the sound for the right Chinese word. Based on class observations, most learners were confused between the second and third pinyin. Hence, they were uncertain of the right word and usually got mixed up between the two intonations. 
Finding 2 Coping Strategies

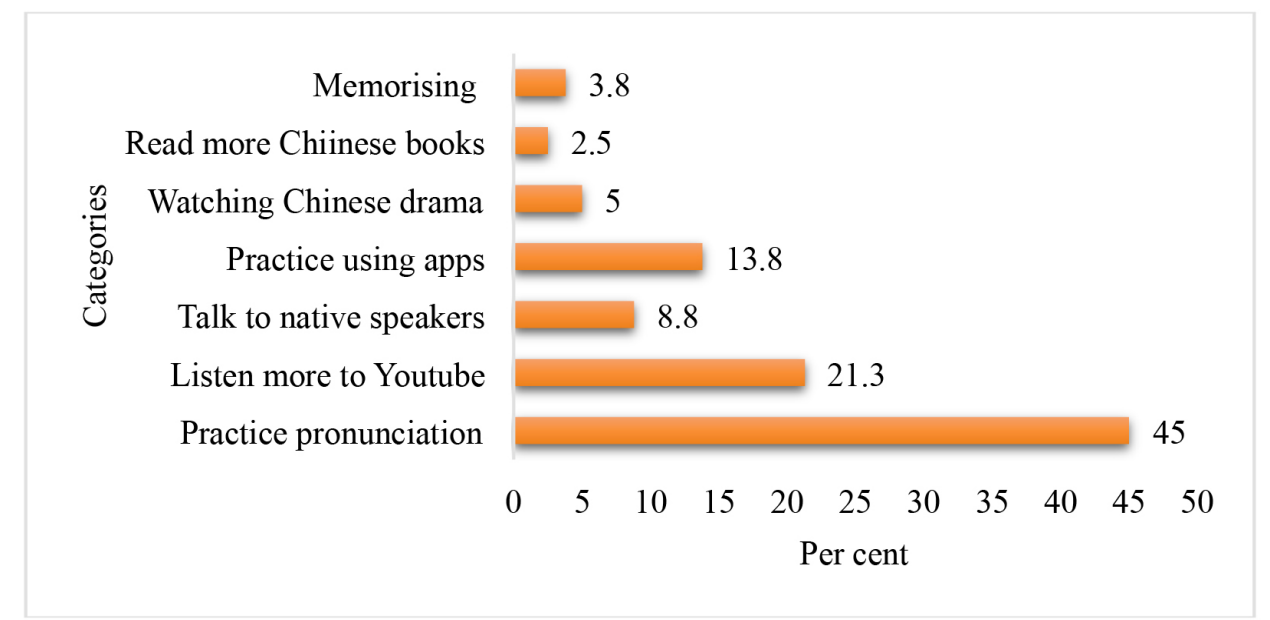

Figure 3: Coping strategies in learning Mandarin that a batch of learners used in Universiti Malaysia Terengganu.

Figure 3 indicates the ways that learners used to cope with their hardship in learning Mandarin. The most obvious was to practice pronouncing the words ( 45 $\%)$. There were also many efforts to use online aids and resources, such as watching YouTube lessons $(21.3 \%)$ and downloading apps to practise the language. Reading and

memorising seemed to be the least methods of coping. Talking to native speakers was moderately practiced probably because it could be done on opportunity only when a speaker was available. Most learners said that practising pronunciations would help improve their conversational skills and remember the right intonations to use.

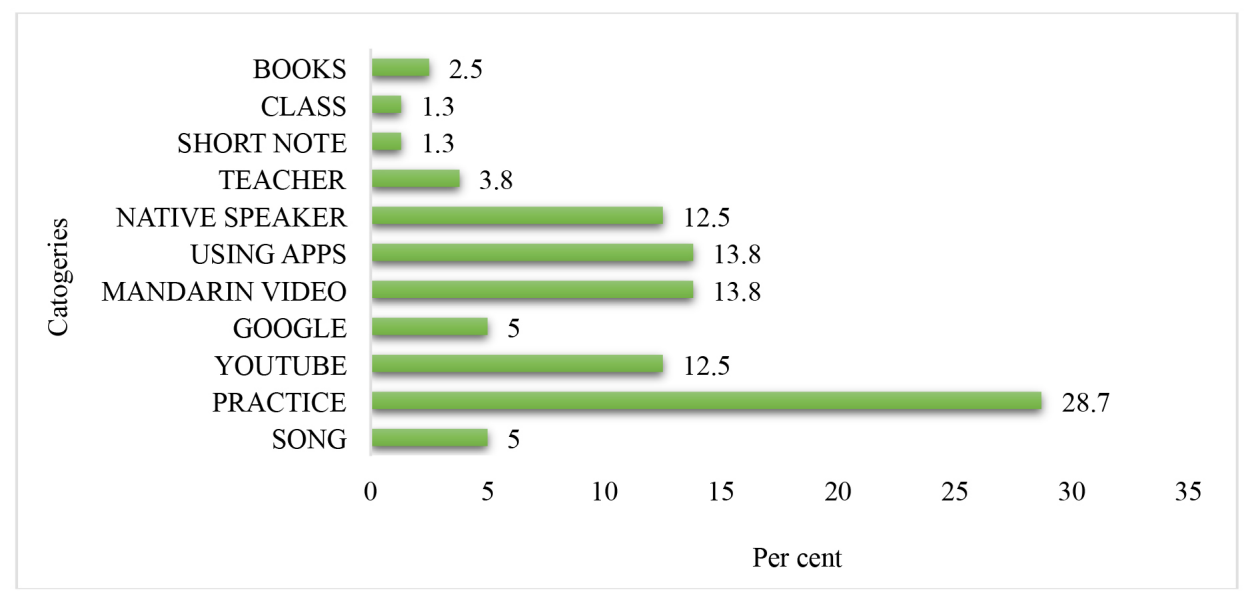

Figure 4: Feedback on strategies that a batch of learners find most helpful in a Mandarin course conducted in Universiti Malaysia Terengganu. 
Figure 4 shows the learners' feedback on the strategies that they found most helpful in learning Mandarin. All the feedback were generally in line with the coping methods stated in Figure 3. Practice (28\%) was definitely the favourite, followed by technological aids and online resources like watching Mandarin videos and using apps (13.8 \% each), besides following lessons on YouTube. Talking to native speakers $(12.5 \%)$ was a moderate favourite as it required building self-confidence to use the language.

The not-so-popular feedback were listening to songs (5\%), research using Google $(5 \%)$, inquiring teachers $(3.8 \%)$, reading books $(2.5 \%)$, taking short notes $(1.3 \%)$ and attending classes $(1.3 \%)$.

The learners' tactics were geared towards technology usage and relying less on traditional techniques, except practising pronunciations and talking to native speakers, where technology could never replace them. Moreover, the students preferred technology-aided learning methods, and $93.8 \%$ of them believed that they could improve their Mandarin that way.

\section{Discussion}

This study found that all learners were having problems with pronunciation, intonation, grammar, Chinese characters, vocabulary, oral communication, giving presentation and composition. The most challenging was learning Chinese characters. This situation was in line with the notion that Mandarin was a complicated language (Jiang \& Cohen, 2018 and Grenfell \& Harris, 2015).

In memorizing strategies, the focus on the shapes of Chinese characters as a whole picture and its components constitute a necessary starting point for this process. The effort involved, however, left little cognitive space for the deployment of time-consuming but higher-level strategies
(Grenfell \& Harris, 2015). Technologyaided methods were also found to be able to ease Mandarin learning. For example, Liu (2010) stated that the Apple iPod Touch was a potentially effective learning tool. Lu et al. (2014) proposed the use of Chinese text entries on mobile phones to evaluate users' learning performance. All these should be recommended in the course to assist students in tackling learning hardship.

The results also showed that the difficult part in learning Mandarin was the ability to speak. This issue appeared to be similarly identified in other studies (Yang, 2015; Jiang \& Cohen, 2018; Wang et al., 2014 and Bryfonski \& Ma, 2019). The researchers found that intonation and pronunciation were the most crucial factors in ensuring communicative goals. The learners could speak correctly and produce pidgin Mandarin by memorizing and training together with technology-aided methods. In this study, all students were concerned with their pronunciations and faced difficulties in mastering them. This was explained by McGinnis (1995) that lexical intonations were "one of the remarkable distinguishing qualities of the Chinese language". Therefore, the instructor needed to consider the psychology aspects like learning anxiety (Hsiao, 2015) and different anxiety levels that occurred in doing various tasks of listening, speaking, reading and writing. Besides, motivation as task orientation, involvement and equity emerged would influence students' motivation to learn Chinese (Ji et al., 2017). All these were the perpetual aspects that must be attended to in future research to bring forth effective teaching of the Chinese language.

To sum up, the students were concerned about their learning, particularly in the aspects of intonation and pronunciation. With the growth of technology, users were provided with ample learning resources, and most of them supported Chinese teaching and learning activities. This 
would be an opportunity for teachers, who should consider integrating technology in their lessons. The findings of this study supported the use of personalized learning was vital in the teaching of Chinese as a foreign language.

\section{Conclusion}

In conclusion, this study helped teachers to understand their learners better, especially being non-native speakers trying to learn the Chinese language. Educators could try to provide a more effective technique to motivate and engage their learners. This study had raised two crucial questions for future research: What were the obstacles that occurred and prevented students from speaking Mandarin fluently in mobile learning, and what were the practical strategies to overcome speaking difficulties in mobile learning? In short, teachers should continuously investigate existing variables and upgrade their approach in finding an efficient method to deal with students' hardship in learning a foreign language.

\section{Acknowledgments}

This research was self-funded. The authors express great appreciation to the staff and learners involved for providing insight and feedback in this research.

\section{References}

Brad, A. (2012) What are the main difficulties in learning a new language (not a programming language)? Quora. Retrieved from The Quora https://www.quora.com/What-arethe-main-difficulties-in-learning-anew-language-not-a-programminglanguage

Chen, J. Y., \& Hsu, D. B. (2017). Spanish learners' acquisition of comprehension strategies in Mandarin Chinese.
Language and Linguistics, 18(3), 327-354. https://doi.org/10.1075/ lali.18.3.01che

Ding, H., Zhang, Y., Liu, H., \& Huang, C. R. (2017). A preliminary phonetic investigation of alphabetic words in Mandarin Chinese. In Proceedings of the Annual Conference of the International Speech Communication Association, INTERSPEECH (Vol. 2017-Augus, pp. 3028-3032). https://doi.org/10.21437/ Interspeech.2017-876

Do, H. S., Hussein, H., Mixdorff, H., Jokisch, O., Ding, H., Gao, Q., \& $\mathrm{Hu}$, G. (2012). Evaluation of benefits from a computer-aided pronunciation training system for german learners of Mandarin Chinese. In Proceedings of the 6th International Conference on Speech Prosody, SP 2012 (Vol. 1, pp. 362-365).

Grenfell, M., \& Harris, V. (2015). Memorisation strategies and the adolescent learner of Mandarin Chinese as a foreign language. Linguistics and Education, 31, 1-13. https://doi. org/10.1016/j.linged.2015.04.002

Hsiao, C. H. (2015). Anxieties and achievement goals: Their relationships in contexts of learning Chinese as a Foreign language. Dissertation Abstracts International Section A: Humanities and Social Sciences, 75(7$\mathrm{A}(\mathrm{E})$ ), No-Specified. Retrieved from http://ovidsp.ovid.com/ovidweb.cgi?T $=\mathrm{JS} \& \mathrm{PAGE}=$ reference $\& \mathrm{D}=\mathrm{psyc} 12 \& \mathrm{~N}$ $E W S=N \& A N=2015-99010-514$

Huang, J. (2000). Students' Major Difficulties in Learning Mandarin Chinese As An Additional Language and Their Coping Strategies. Eric.

Ji, C., Duffield, S., Wageman, J. J., \& Welch, A. G. (2017). Student perceptions of the classroom learning environment and motivation to learn Chinese. Chinese as a Second Language (-) Chinese as 
a Second Language (-). The Journal of the Chinese Language Teachers Association, USA, 52(2), 111-126. https://doi.org/10.1075/csl.52.2.01ji

Kaan, E., Barkley, C. M., Bao, M., \& Wayland, R. (2008). Thai lexical intonation perception in native speakers of Thai, English and Mandarin Chinese: an event-related potentials training study. BMC Neuroscience, 9, 53. https://doi.org/10.1186/1471-22029-53

Lan, Y., Lin, Y., Kao, C., Chang, K., Sung, Y., \& Liu, T. (2014). A Study of Mobile-Assisted Oral Communication in Mandarin Chinese as a Second Language, (February 2010).

Liu, Y. (2010). Predicting Chinese text entry speeds on mobile phones. Time, 2183-2192.

Lu, J., Meng, S., \& Tam, V. (2014). Learning Chinese characters via mobile technology in a primary school classroom. Educational Media International, 51(December 2014), p166-184. https://doi.org/10.1080/095 23987.2014.968448

Luo, H. (2015). Chinese Language Learning Anxiety: A Study of Heritage Learners. Heritage Language Journal, 12(1), 22-47.

McGinnis, S. (1995). Student attitudes and approaches in the learning of written Chinese. In Annual Conference of the American Association for Applied Linguistics, Long Beach, CA.

McLoughlin, I. V. (2007). Intonation discrimination in Mandarin Chinese. In 2007 IWSSIP and EC-SIPMCS - Proc. 2007 14th Int. Workshop on Systems, Signals and Image Processing, and 6th EURASIP Conf. Focused on Speech and Image Processing, Multimedia Communications and Services (pp. 296-299).
Mohamed, O., \& Wei, Z. (2018). Motivation and satisfaction of international student studying Chinese language with technology of education. In Proceedings - 6th International Conference of Educational Innovation Through Technology, EITT 2017 (Vol. 2018-March, pp. 272-277). https://doi. org/10.1109/EITT.2017.73

Peipei, W. (2018). Cross-Linguistic Perception and Learning of Mandarin Chinese Sounds by Japanese Adult Learners. ProQuest Dissertations \& Theses Global. Retrieved from https://search.proquest.com/docview/ 2010390986? accountid=13042 http:// oxfordsfx.hosted.exlibrisgroup.com/ oxford?url_ver=Z39.88-2004\&rft val_fmt=info:ofi/fmt:kev:mtx:dissertat ion $\&$ genre $=$ dissertations $+\% 26+$ theses \&sid=ProQ:MLA+International+Bibli ography\&atitle

$\mathrm{Su}$, J. (2018). Reassembly of plural and human features in the L2 acquisition of Chinese by adult Korean speakers. Second Language Research. https:// doi.org/10.1177/0267658318789223

Sun, M., \& Summers, R. (2014). Chinese Adult Second Language Learners' Learning Strategy and Communicative Strategy Use. Journal of Second and Multiple Language Acquisition JSMULA, 2(1), 22-35.

Ting, H. L., Yeo, J. Y., \& Chin, V. (2016). Mandarin Language Learning Anxiety Among Non-Chinese Learners: A Case of Universiti Teknologi MARA. Issues in Language Studies, 5(2). https://doi. org/10.33736/ils.1633.2016

Williams, M., \& Burden, R. (1997a). Motivation in language learning: a social constructivist approach. Recherche et Pratiques Pédagogiques En Langues de Spécialité - Cahiers de l'APLIUT, 16(3), 19-27. https://doi. org/10.3406/apliu.1997.1201 
Williams, M., \& Burden, R. L. (1997b). Psychology for Language Teachers: A Social Constructivist Approach. ERIC.

Wong, L. H., Looi, C. K., \& Boticki, I. (2017). Improving the design of a mCSCL Chinese character forming game with a distributed scaffolding design framework. Research and Practice in Technology Enhanced Learning, 12(1).

Xu, Q., \& Peng, H. (2017). Investigating mobile-assisted oral feedback in teaching Chinese as a second language. Computer Assisted Language Learning, 30(3-4), 173-182. https://doi.org/10.1 080/09588221.2017.1297836

Yang, B. (2015). Perception and production of Mandarin intonations by native speakers and L2 learners. Perception and Production of Mandarin Intonations by Native Speakers and L2 Learners. Berlin: Springer Heidelberg. https://doi.org/10.1007/978-3-66244645-4
Ying, L. C., \& Wah, F. P. (2016). AppMFoL mobile application development for learning mandarin as a foreign language. International Journal of ADVANCED AND APPLIED SCIENCES, 3(11), 47-51. https://doi. org/10.21833/ijaas.2016.11.009

Yong, Y., Sharifah Intan Safina, S., \& Muhammad Nubli, A. (2016a). A Study on Performance of Mandarin Speaking Test among Non-Native Speakers through Bio-Feedback. The Social Sciences, 13(4), 780-786.

Yong, Y. M., Cheng, C. Y, \& Lee, C. K. (2016b). Analysis of Practical Mandarin during Short-term Learning and Travelling Program in China among Non-Chinese Students. International Language and Tourism Conference 2016(ILTC 2016), 2016(Iltc). Retrieved from https://www.researchgate.net/ publication/315115362

Zhang, Y., Hu, Y., Chu, M., Huang, C., \& Liang, M. (2008). Mandarin intonation error detection. Qinghua Daxue Xuebao/Journal of Tsinghua University, 48(SUPPL.), 683-687. 